\title{
HARMONIZATION BETWEEN ARCHITECTURE AND NATURE THROUGH TRADITIONAL JAPANESE SCREENS
}

\author{
E. BEITA \& A. FUJII \\ Department of Architecture, University of Tokyo, Tokyo, Japan.
}

\begin{abstract}
Harmonization between architecture and nature is one principle deeply rooted in traditional Japanese architecture, influencing all aspects of space creation. Buildings are not seen as individual objects, but as part of the existing environment, resulting in the development of design principles which enhance these qualities. Although there are many components in traditional architecture which promote these principles, one of the most important ones is boundaries. Through the precise control of boundaries, a space can be given a new meaning and even perceived in a new manner. Traditional screen systems known in Japanese as 'shoji' give spaces the flexibility needed to adapt to a changing environment, given the inhabitants control of views, illumination and ventilation. This adaptability of traditional spaces has been studied through a case study of a single tea room, which was then simulated through 3D modelling software, permitting the analysis of the space during different times and seasons. The results highlight the important design principles used to improve the interaction of spaces, while showing possible applications in urban spaces in the creation of adaptable screen systems suited towards a constantly changing environment.

Keywords: boundaries, building and nature, Japanese traditional architecture, screen system, urban space.
\end{abstract}

\section{INTRODUCTION}

For centuries traditional Japanese architecture has created spaces which can fully respond to their environment, adapting and changing as needed. These spaces also express a mastery of the control of light, views and boundaries. In Japanese, boundaries are known as 'Kyokai'; this idea of framing and adding limits is an important tool in the articulation of spaces. Over time, architects and tea masters were able to refine design techniques to create spaces full of mystery and beauty. Japanese culture also regards nature with the highest respect, further influencing a deep connection to it. A building is never seen as one individual space, but as something part of the surroundings. For this reason, traditional spaces are always in constant connection with nature. Both interior and exterior work as one, and through this they are able to complement each other. Furthermore, the precise design of the building adds limits to the exterior, framing it like a painting, a natural painting which is always changing and expressing the beauty of every season. Through this research it has provided a clear understanding of the importance of traditional design in improving the quality of spaces. In order to better understand these ideas, this research focuses on a case study of a single traditional space, one which shows an expanded awareness and articulation of the environment.

\section{METHODOLOGY}

The study gathered both primary and secondary data. Primary data was collected through field surveys conducted from October 2005 to March 2010. Background research included site visits to over one hundred traditional spaces in Japan. At the same time it included interviews with temple monks, tea ceremony practitioners, residents and other researchers. The interviews included questions related to the use and application of paper screens and boundaries in traditional Japanese architecture, including its flexibility and ability to control views. This allowed for the documentation of different types of paper screen systems, until one example exhibiting unique characteristics was found. The selected system showed increased adaptability in the movement of panels for controlling 
illumination, ventilation and views. Also, its position on the wall, covering only the upper portion and leaving the bottom area open was unique among all the visited sites. Secondary data were obtained through published material regarding Japanese architecture, history and tea ceremony. Special attention was then given to tea ceremony spaces, since they show the greatest understanding of the creation of views. Among some of the literature was the book, 'Kobori Enshu, A Tea Masters Harmonic Brilliance' [1]. The book, as well as an interview with the author provided a detailed understanding into the importance of paper screens in traditional architecture. Next, in order to study the space in more detail, a 3D model of the 'Bosen' tea room was created with the software 3D Studio Max Design 2009, permitting the simulation of accurate lighting and atmospheric conditions. At the same time, within this software various steps had to be taken in order to simulate actual site conditions. The creation of accurate site materials was accomplished by using existing photographs, which were then used to generate materials for use in the $3 \mathrm{D}$ model. In the case of exterior landscape, aerial photographs were imported into the 3D software, where a 3D landscape was built. As for the atmospheric conditions, a clear sunny sky was maintained for all simulations. Finally, simulated renderings were created from sunrise to sunset during different seasons, in order to see how the space changed during the day, year and under various shading variations.

\section{THE BOSEN TEA ROOM AND HIUNKAKU PAVILION}

In 1643, Kobori Enshu, a Japanese tea master designed his personal residence, which eventually became the Koho-an Temple after his death in 1647[1]. Although he was famous for his ideas of tea ceremony, throughout his life he was able to work on a variety of projects, ranging from the construction of castles, gardens, government buildings and tea rooms [2]. While growing up, Enshu lived near Lake Biwa, the largest fresh water lake in Japan, so upon retiring he decided to bring the memory of his childhood to his tea room, Fig. 1. The name 'Bosen' can have different interpretations, one if which can be 'Forgetting about the Net' meaning, 'When the fish is caught one needs no net', which suits the tea room perfectly since in relates to water [3]. However, in order to re-create the essence of his childhood, Enshu used one of his most powerful tools, the creation of boundaries. Through the design of a unique paper screen, the space is controlled carefully, in such a way that the observer can view the tea room in relation to Lake Biwa. As a whole, one important theme in the design is the idea of being near water, which can be seen through the incorporation of hints relating to water. First, the tea room incorporates small wooden rails which resemble that of small boats. Second, the design of the garden is meant to represent different views of Lake Biwa. Next, the garden is organized so that one can see vast open areas of plain dirt, surrounded by islands of moss, the dirt representing water. Finally, and the most important is the creation of water ripples on the ceiling of the tea room [4]. By precisely positioning a wash basin in front of the tea room, at certain times of the year water is reflected from the wash basin into the tea room, giving the impression to the spectator the sense of being near water.

The second space, also located near the 'Bosen' tea room is the Hiunkaku Pavilion, which can be found inside the temple Nishi Honganji. Although this location was not part of the case study, it also uses a paper screen system similar to the 'Bosen' tea room which is bigger and more mechanical, Fig. 1. Hiunkaku pavilion was built in 1587 by order of Toyotomi Hideyoshi, a Japanese feudal lord during the Momoyama period in the 15th century. Hiunkaku, which means a 'Pavilion of Floating clouds', is a three-storey building consisting of a tea room, bath house and a room for resting [5]. Something interesting about this pavilion is the way it is accessed, either by crossing a stone bridge over the pond or more unique by boat. This is when we come to the Funairi room, which can be accessed directly from the boat after opening a set of horizontal doors in the floor. Upon docking in front of the pavilion, a set of stairs leads from the pond into the room, giving the space its name, Funairi, literally meaning a space which is approached by boat. 

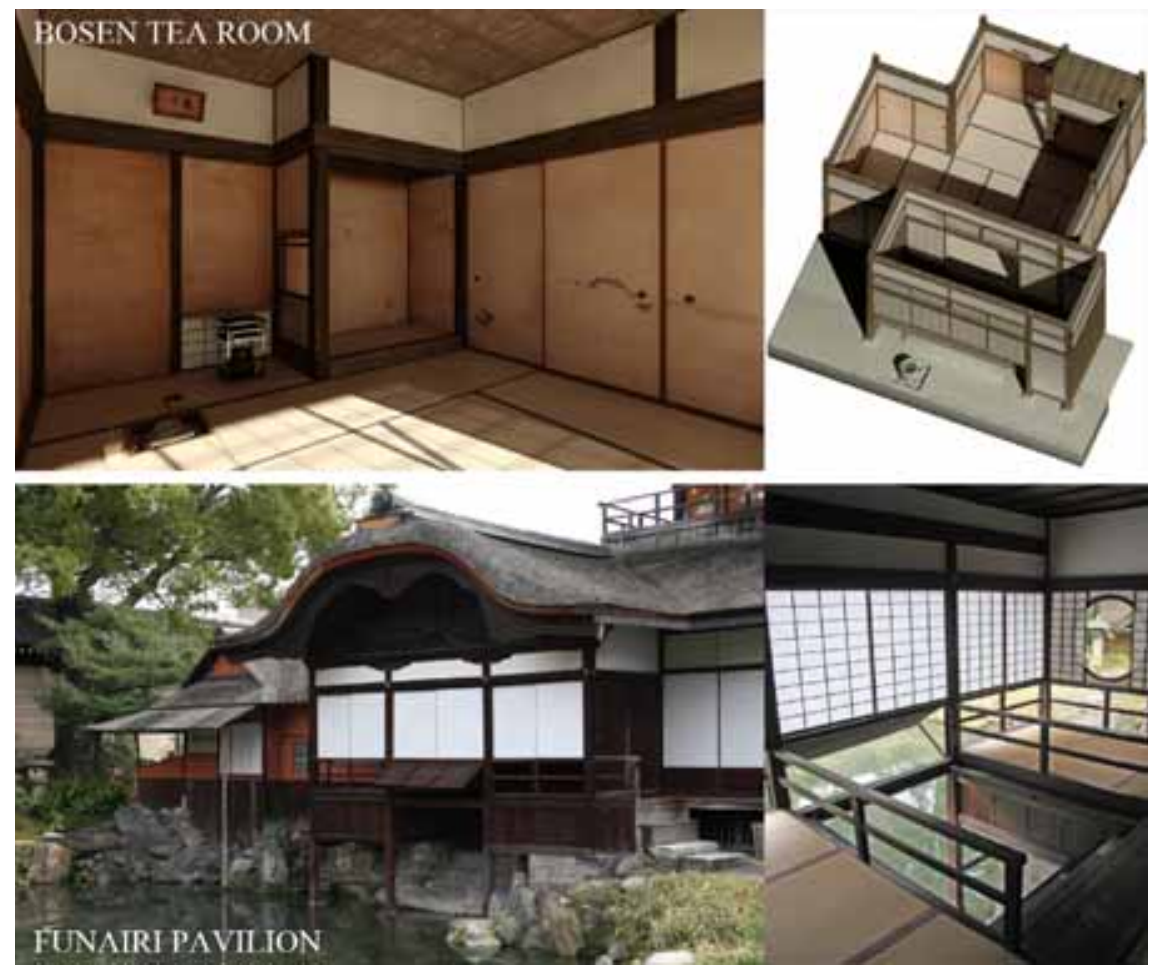

Figure 1: 'Bosen' tea room and Funairi pavilion.

\section{A FULLY ADAPTABLE SPACE}

One of the unique qualities of the 'Bosen' tea room is its capability to adapt to changing conditions through the year. The tea room is able to make use of its design to improve the quality of the space, in summer the flexibility of the sliding doors and paper panels allow the space to open to the outside, improving ventilation and cooling the space. At the same time the different panels in the space can be used in various combinations to control the amount of illumination and the number of views. This flexibility allows the building to open up to nature, becoming a part of the landscape. Next, through the precise control of boundaries, the space is able to frame specific elements of the landscape. The scene can be cropped to only to show certain areas, and so, given the designer the freedom to change the perception of the exterior space. Finally, through the understating of natural effects, the tea room is able to make use of the creation of water ripples to create an atmosphere suited for the tea master, Fig. 2. By themselves, each one of these qualities can improve the atmosphere; however, when they work together they create a space which is fully adaptable and aware of its environment.

\subsection{Incorporation of natural elements}

The 'Bosen' tea room makes use of several natural elements in its design. Each one has a distinct effect on the character of the space; these elements are represented by nature, representations of nature and effects of nature. By making use of these a space can be transformed to evoke a feeling of a distant landscape, by conjuring a deep relationship with the observer, who will see each natural element as a reminder of something far, or even, a memory from the past. 


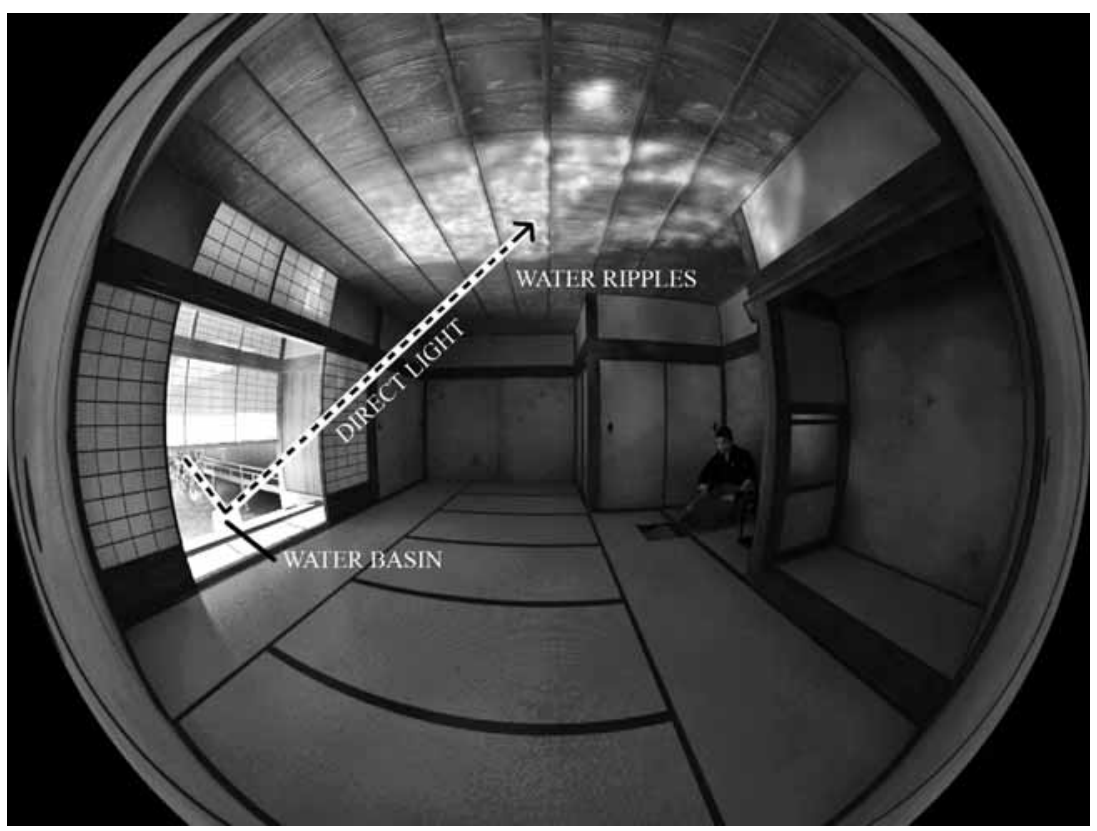

Figure 2: Creation of water ripples on the interior ceiling of the 'Bosen' tea room.

The first of these elements is represented through the design of the garden. By itself, the entire garden is a 'natural element'; however, the designer goes further to create a garden which derives its design from the area surrounding Lake Biwa. Lake Biwa is famous for its eight views, which are represented through the design of the garden, and can be seen from different areas within Koho-an Temple. If the garden is viewed from the 'Bosen' tea room, it is possible to see various shrubs, islands of moss and open areas of plain red dirt. All these elements are designed to represent mountains through shrubs and Lake Biwa through open areas of red dirt. Second, 'representations of natural' elements are shown through paintings of mountains located on different walls. These can be found on several of the sliding doors and on the back and side of the alcove. From the seating position of the tea master, two views are possible, one a framed view of the garden and second a framed view of one of the paintings. This is achieved through the design of the alcove, which incorporates a window like frame on the wall next to the tea master. Through this, a simple painting is enhanced and treated almost like a natural view, giving it a deeper meaning. Third, an 'effect caused by nature' is represented through the use of a water basin placed in front of the tea room, which reflects water ripples on the interior ceiling of the tea room, Fig. 2.

\subsection{Creation of boundaries}

Boundaries add a frame to the world, adding limits and cropping the exterior scenery to create a perfect view. Through boundaries a designer can show and express his personal ideas as a living painting. In the 'Bosen' tea room, boundaries play a big role in the perception of the space, by only showing the inhabitants a small portion of the garden. Furthermore, the creation of boundaries is not limited to the architecture, but work together with other boundaries created by the garden. Directly in front of the veranda lies a rectangular shaped shrub which hides a large portion of the garden, 


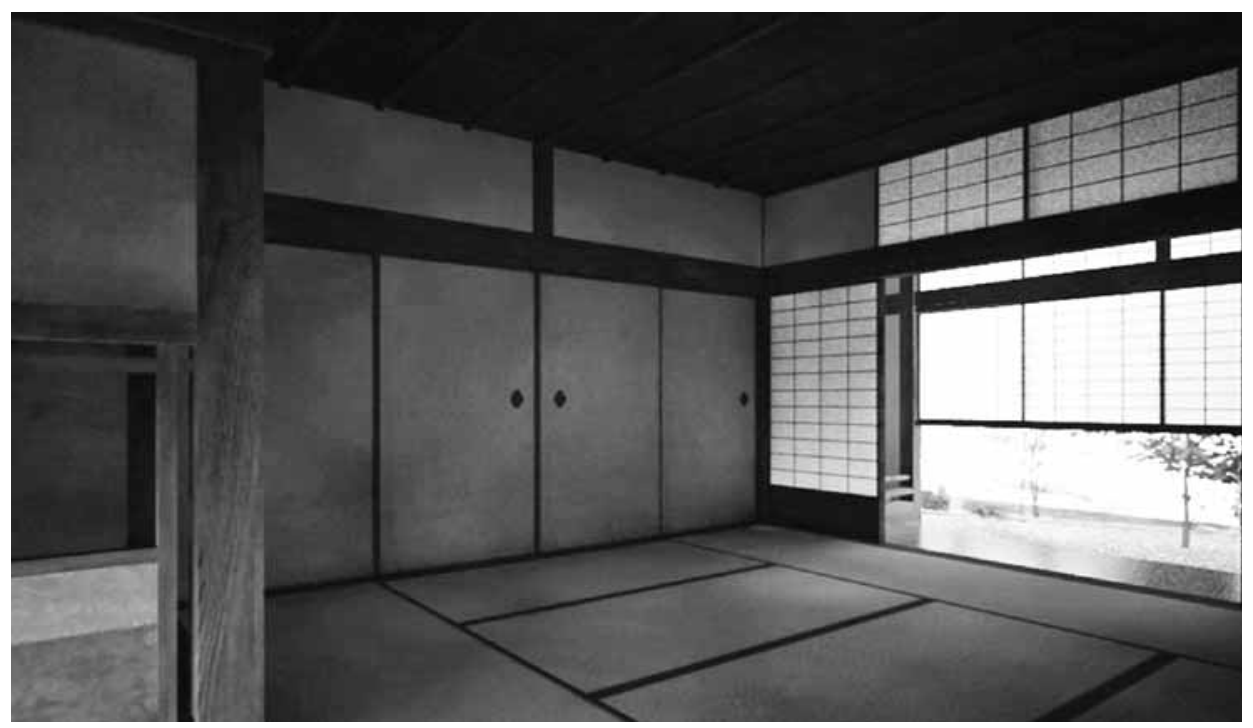

Figure 3: View of the garden from the tea master's seating position.

while at the same time directing the eye to a more important view. The inhabitants are never given a full picture of the exterior, but are left to wonder what exists outside. The final picture captures a beauty unique to each person, created on the moment according to the quality of light, boundaries and viewing position.

In Japanese literature, one author described this quality as 'a Japanese room might be likened to an inkwash painting, the paper-paneled shoji being the expanses where the ink is the thinnest, and the alcove where it is the darkest. Whenever I see the alcove of a tastefully built Japanese room, I marvel at our comprehension of the secrets of shadows, our sensitive use of shadow and light... Where lays the key to this mystery? Ultimately, it is the magic of shadows' [6]. In the 'Bosen' tea room the framed view was picked by the tea master to show a certain connection, which he could then show his guests as they enjoyed tea, Fig. 3. Although different areas of the scene can be framed, by showing a controlled view of the ground, it provides enough information to know the surrounding conditions without seeing the entire scene. Each season can be experienced by simply seeing rain, leafs, or snow falling on the lower area of the view. At the same time, since the exterior screen has movable panels, different areas of the garden can be framed during the year, each time highlighting the beauty of each season.

\subsection{Increased flexibility}

Like many traditional Japanese spaces, one element which becomes clear is its flexibility. Although Japan has four seasons, summer is one of the most extreme ones, having high temperatures and humidity. For this reason, traditional architecture is designed to provide escape from summer. In the 'Bosen' tea room, this flexibility can be achieved through the many paper screens available in the space. In total the screens have several uses, the inner paper screen works as a sliding door, providing privacy without losing natural illumination. Next, the exterior paper screen is designed with multiple sliding panels, permitting control of the scenery, illumination and ventilation, Fig. 4. Finally, above these screens, near the ceiling, smaller screens are used to further control and enhance ventilation in the space. 


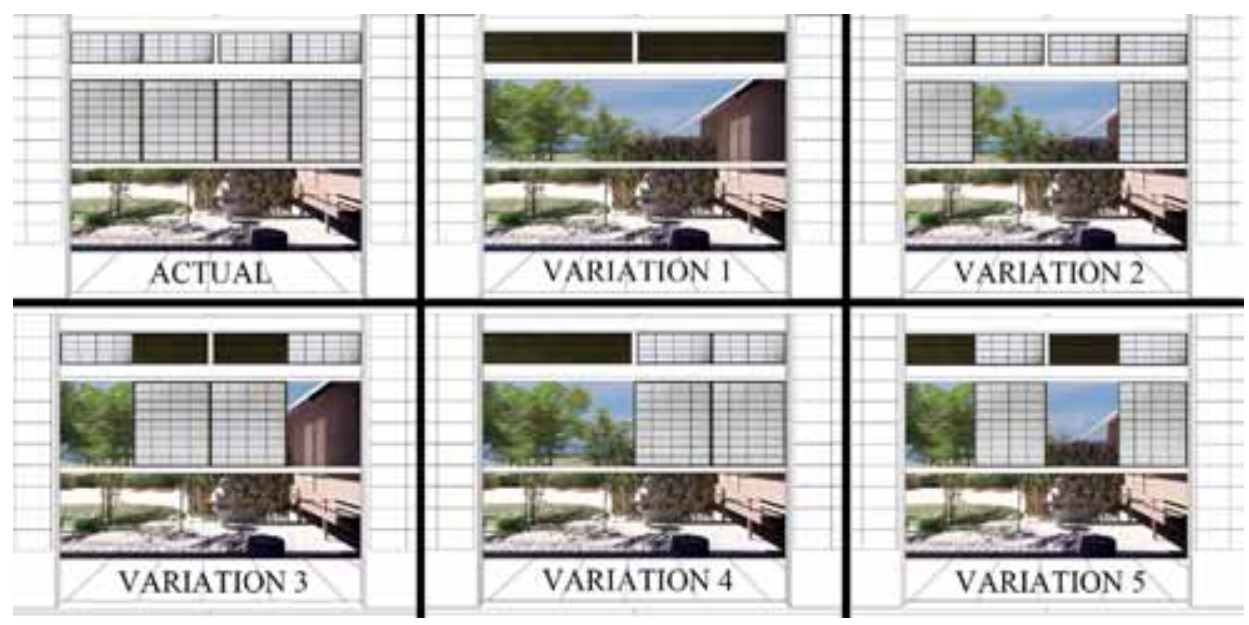

Figure 4: Flexibility of a paper screen in controlling views, illumination and ventilation.

\subsection{Control of illumination}

Due to the west orientation of the tea room, direct sunlight becomes a constant element in the interior space, and at times reaching the tea master's seating position. At certain times this amount of direct light might be needed to create a certain feeling or effect inside the tea room. One such effect is the reflection of water ripples on the ceiling. On the other hand, during tea ceremony, too much direct light can become a problem for the host, especially in spring. During this season, direct light will completely cover the hosts seating area in the evening hours. If a person were to conduct tea ceremony during this time, direct light will hit his body and face, Fig. 5. For this reason the tea room makes use of multiple shading devices which can be used in different combinations to control the amount of light. The exterior paper screen acts as the main shading device; however, during summer a bamboo screen will be added in front of it to cut the intensity of light. If this is still not enough, the interior paper sliding doors can also be closed to provide a third layer of shading. Overall, this system of multiple layers of shading creates a space which can adapt to the changing light conditions throughout the year.

\section{ADVANTAGES OF THE BOSEN TEA ROOM}

Overall the 'Bosen' tea room has many advantages resulting from its design: (1) It has the ability to make a space feel bigger. (2) It improves the interaction of the space to its surroundings. (3) It provides flexibility in controlling unwanted views. (4) It improves control of illumination and ventilation.

\subsection{Expanding small spaces}

One main advantage is the ability to take a small room and expand its boundaries through a combination of design principles which control the interaction between interior and exterior. Boundaries are able to crop, hide and show certain views, and thus, establishing a link between different areas. By controlling the views, it transforms the paper screen into a blank sheet of paper, to be completed by each person and their imagination. As a whole, the room provides each person different clues of what lies outside. It doesn't matter if the space outside is small or is lacking in views, the observer 


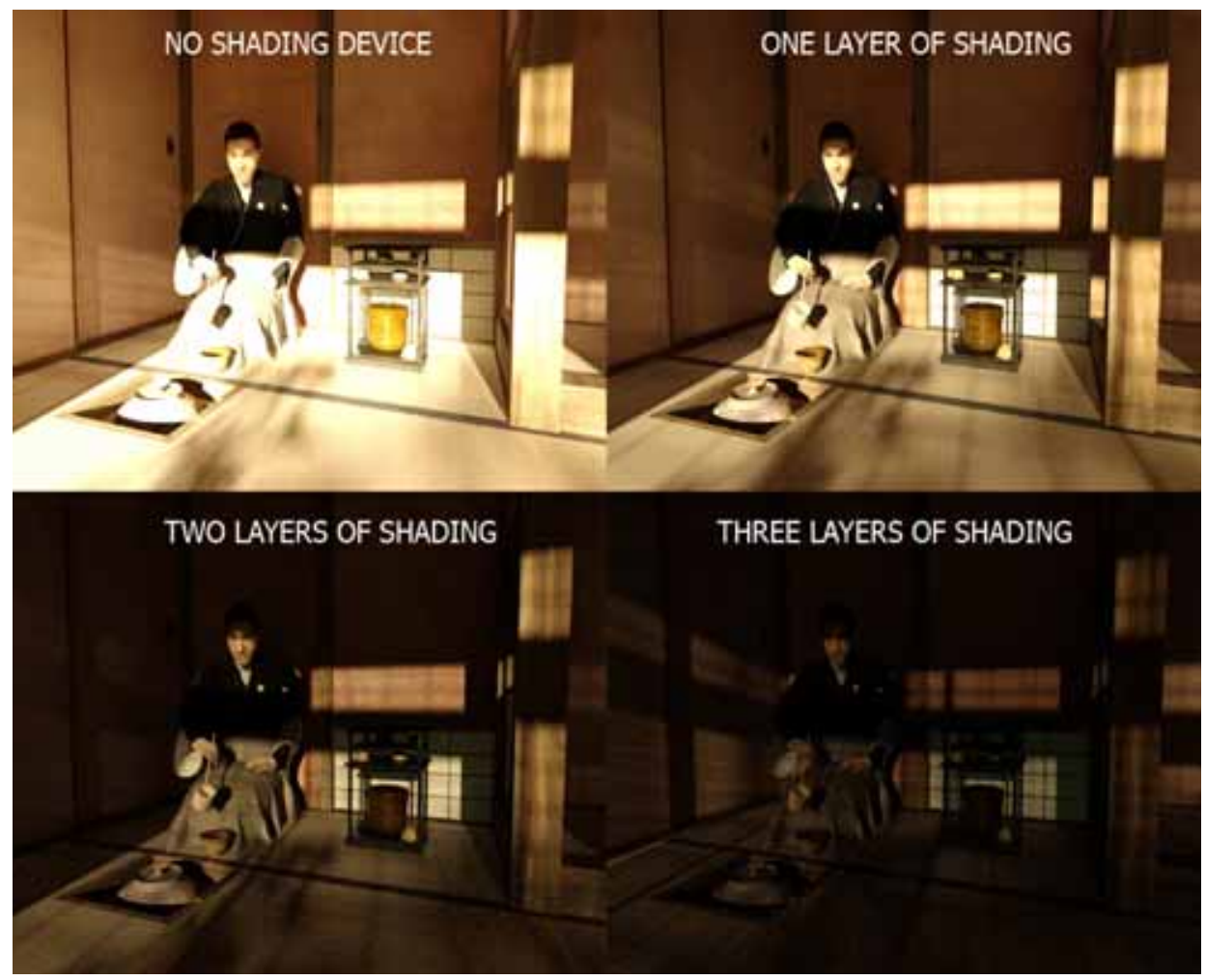

Figure 5: Control of illumination through various layers and combinations of shading devices.

never sees these. Finally, all the person has to do is put the hints together, look at the framed view and imagine the rest of the scene. Through this a small space is given new expanded boundaries, losing the qualities of a confined space.

\subsection{Connecting with nature}

The tea room doesn't just create a view to the garden; instead it makes the garden part of the building and observer. The building itself allows the inhabitants to make a connection to the exterior by selecting a specific view. Through the design of the garden, hints of a distant landscape are created, bringing the essence of a faraway place closer. The boundaries provide a focal point to interact with nature, allowing one to observe changes throughout the year. Overall the connectivity of the tea room makes it part of its environment, and not just a building in the garden.

\subsection{Control of unwanted views}

By implementing different paper screens in different parts of the space, the tea room is able to control views as needed. As each of the paper screens can move left, right or be removed, it allows for multiple combinations to crop the exterior. Through this, the tea room is able to hide certain elements from view, including the horizon line, other buildings and landscape scenery. If the horizon line is seen, then it makes it possible to determine the size of the exterior space, while other buildings 
and landscapes would point out the location of the site. Through precisely placed paper screens, unwanted views are hidden, making it possible to reinvent the exterior landscape.

\subsection{Control of illumination and ventilation}

As with other aspects in the space, the tea room offers increased flexibility in the control of illumination and ventilation. This is due to the Japanese shoji screens which provide multiple combinations in accordance with the amount of opening. During any time of the year, the shoji panels can be moved to increase or decrease ventilation, becoming most useful in the summer months, when the building can completely open to the exterior. In the same way, this flexibility allows for the illumination of the room to be controlled as needed, either by opening panels, or using a layering of different panels to decrease the amount of light. In summer, shoji panels dilute the sun's strong rays, while in winter, the shoji paper panels work to gather and intensify light.

\section{PRACTICAL APPLICATIONS OF JAPANESE TRADITIONAL DESIGN IN URBAN SPACES}

One motivating factor in this analysis is the promotion of traditional Japanese design ideas, many of which have gone through centuries of refinement, and so creating new spaces which can benefit from these qualities. It is not the intent to re-create what was created in the past, but to use the knowledge to create a space for today. The final space might not look like the original; but it will exhibit the essence of traditional Japanese design. This essence can be expressed through a wall system which acts as more than just a window. By carefully selecting and framing views, as well as improving the interaction between interior and exterior and allowing each person to modify the system as needed, it results in a space which follows traditional design principles for the creation of spaces.

\subsection{Planning}

In traditional space every element is given immense attention in order to create the best possible harmony. Also, through an understanding of the planning process a space can be made very personal, even able to conjure up scenes of distant landscapes. Paper screens enhance illumination in small spaces while improving ventilation and flexibly, so through the creation of a wall system based on the characteristics of the 'Bosen' tea room, it will be one step forward in improving the quality and adaptability of spaces. However, when creating new spaces, it is very important to consider the movement of the sun, exterior natural views, creation of boundaries and ways the space can adapt to changing conditions, whether environmental or space wise. The creations of gardens are beneficial in establishing a focal point for the inhabitant, and so, should be used in spaces meant for relaxation. These gardens don't need to be large, instead they need to be designed in conjunction with a wall system which frames it and brings focus to it. In Japan, the lack of space results in vertical gardens on the walls dividing two properties. These walls are typically made of a porous material where moss or other plants can grow. However, it is understandable that having exterior gardens is not always possible in urban settings, and in this case consideration should be given to the creation of interior gardens. As shown in the 'Bosen' tea room, through the design of the alcove, an interior wall painting of mountains can be given a higher meaning when it is framed by interior boundaries. However, a natural view doesn't need to be that of a garden located on your site; a garden can become any number of natural views ranging from the sky, trees, water elements, to even distant mountains. The important point is to use boundaries to capture these elements. Once this is done, a distant landscape is given a connection to your site, becoming a part of it. The research has also shown that many 
elements are needed to create hints for a person as he views and inhabits the space. These elements can be incorporated in the design of the space by highlighting and capturing certain areas of a view, areas which the observer can relate to or find relaxing. Also, the design of furniture, paintings and natural effects like water ripples can play a big role in creating a space suited for a certain person. By keeping to these principles it will provide improved flexibility and interaction with the environment, while maintaining the essence of a traditional Japanese space.

\subsection{Benefits}

The benefits are seen in an adaptable space suited for each person. This unique quality, reacting to a variety of elements and only reaching its full potential through the interaction of people, becomes beneficial quality through increased adaptability. These qualities have proven to have positive effects in many traditional spaces over the course of centuries, making their transition to urban spaces beneficial in providing improved control of unwanted views while still promoting interaction with the environment. At the same time, another important benefit for urban spaces is the ability to improve the quality of small rooms by expanding their visual limits through the precise creation of boundaries. Japanese screens work more as wall systems instead of windows, and so, are able to provide improved control of many elements. In traditional architecture the variety of these screens are immense, many having different panel movements suited for specific conditions. Some are used for viewing the ground, middle and upper area of the scene. However, the basic arrangement of hiding the upper area and opening the lower area is one of the most common designs. This design continues to be used today in contemporary architecture, including the Japanese housing market [7]. This basic design has become very useful in the construction of new homes that lack exterior space. Through paper screens, homes are able to hide neighboring constructions, while enhancing the little green area which they have. Unlike the past, where each tea master could design their own exterior environment to provide the best possible views, in urban spaces this becomes difficult. Urban spaces are constantly changing and at the same time they are full of unwanted views.

\subsection{A Japanese screen for urban space}

Paper screens can have positive applications if used in urban spaces, but only after adapting to new conditions. So what are these conditions and to what spaces are they suited best? In looking at the traditional use of paper screens in Japan, it is observed that such devices are mostly limited to small rooms. If the screen was to be used in a large area, the effect would disappear, light would vanish, the view would become lost and the connection between interior and exterior would be lost. A person needs to be close to the screen to fully appreciate its limits, and to feel part of it. This being said, the influence of traditional screens would be beneficial on the creation of new screens better suited for small urban spaces. At the same time, new screen types need to be able to enhance the environment in the same way as a traditional one, which is to offer improved control of illumination and ventilation. However in urban space, they need to be able to adapt to a constantly changing environment, and so, they require increased flexibility. In some cases natural views exist in urban spaces, but they must be filtered and captured. The screen panels also need to posses improved movements to adapt to a view which may occur anywhere on the wall. Overall, through the application of a screen system which follows traditional design principles giving importance to the control of views, illumination and ventilation, it can result in the development of better wall systems to interact with your environment. 


\subsection{Combining multiple paper screen designs}

One way to increase the flexibility of traditional paper screens can be accomplished by combining different screen designs. For instance, one type of screen is known in Japanese as Yukimi Shoji, Yukimi referring to the act of viewing snow, and Shoji to a screen, Fig. 6. Although the name refers to snow, it can be used for viewing any season. The basic design is the same as a sliding screen, where each panel can move left or right serving as a divider or entrance. But unlike other screens this one has lower panels which can move vertically to reveal the garden. In the case of the 'Bosen' tea room, the lower area of the screen is always open, with only the upper area providing horizontal movements. In other cases, screens may highlight areas closer to the ceiling; these are known as moon-viewing screens. Overall, most screen systems have three types of movements possible by the

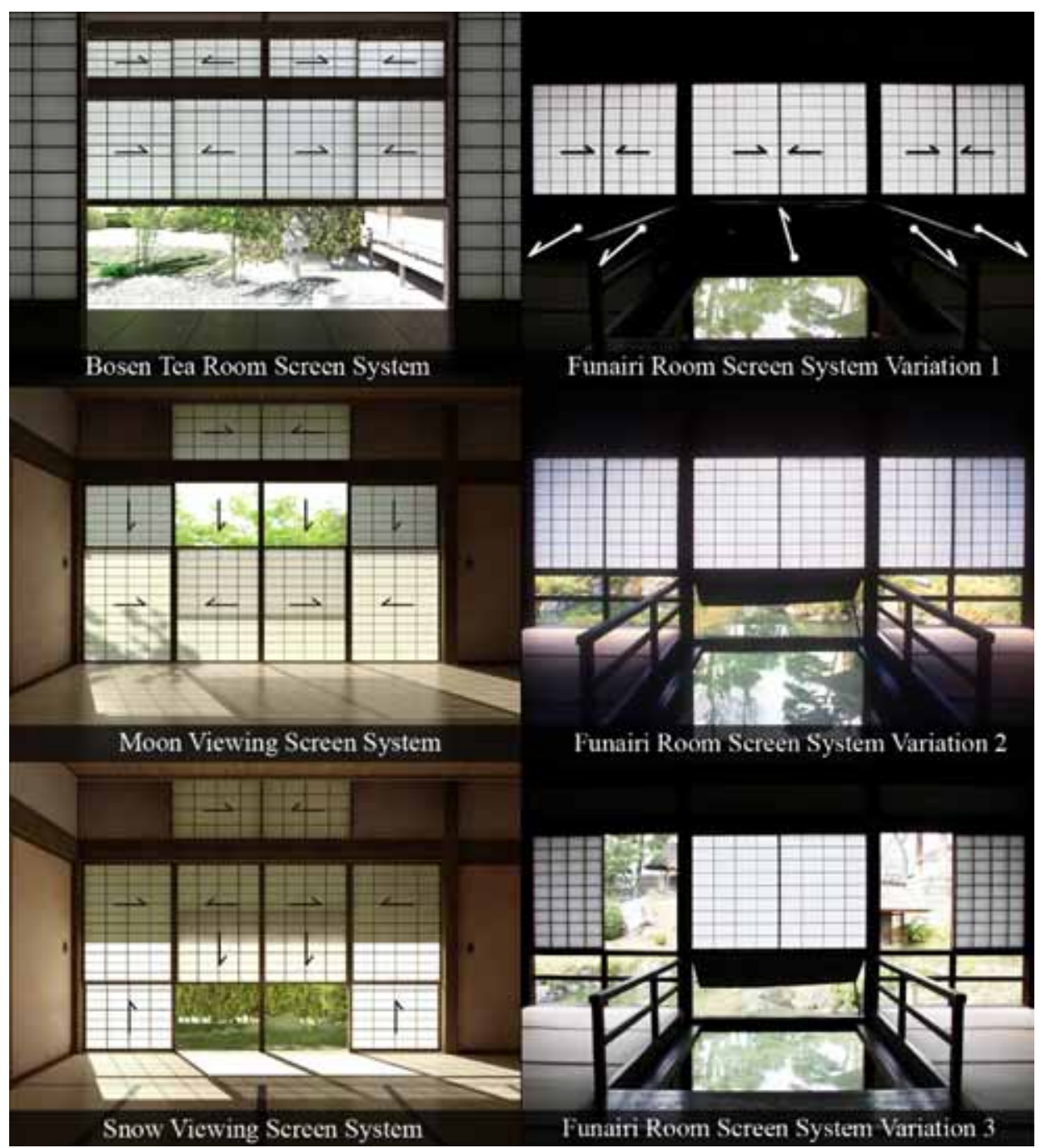

Figure 6: Types of paper screen wall systems found in traditional Japanese architecture. 


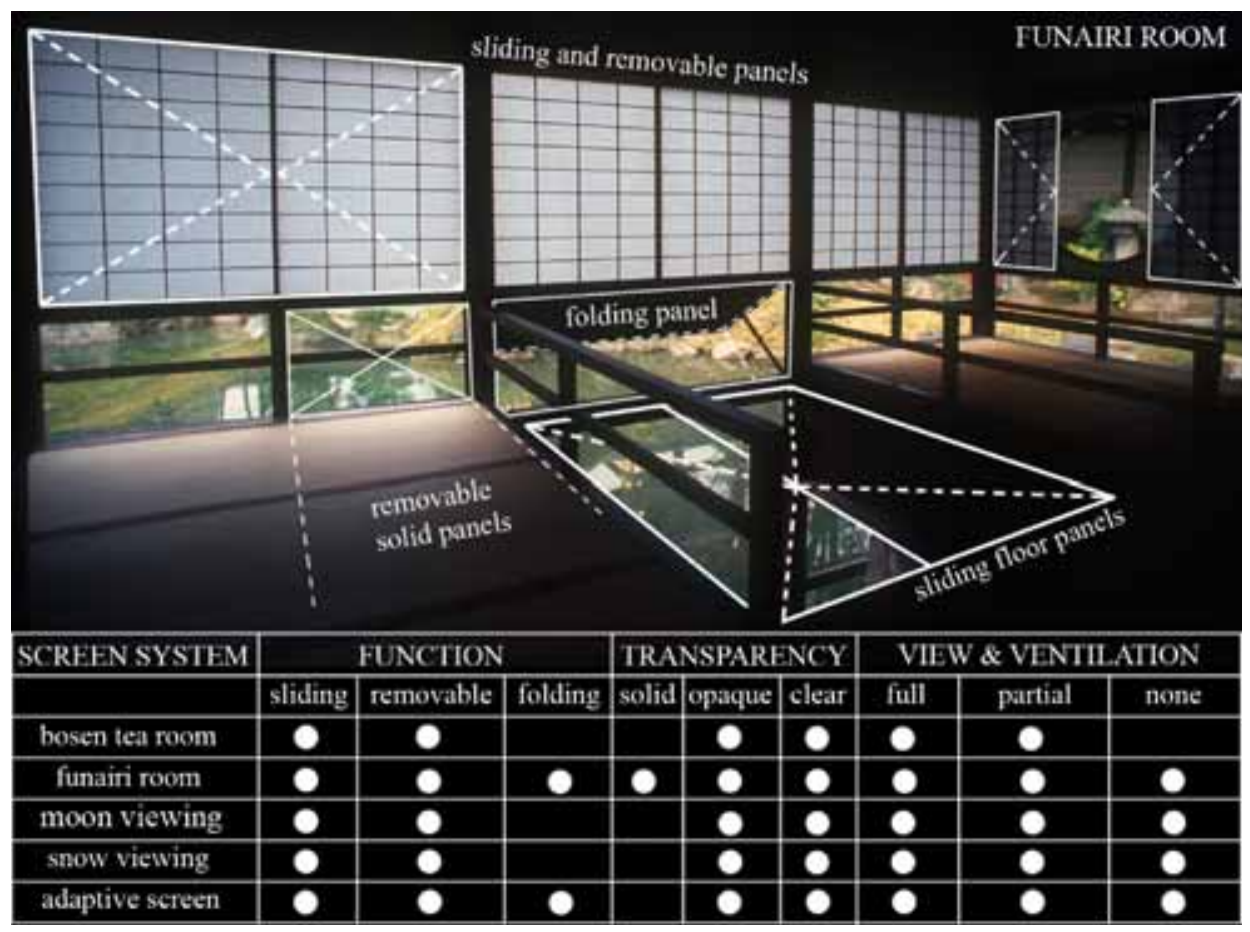

Figure 7: Comparative movements of different Japanese screens.

panels, these being, sliding, folding and removable panels, which can be used individually or in combination, Fig. 7. Although sliding and removable panels are very common, the use of folding panels is rare in a screen system, especially when all three are used together. For instance, the 'Bosen' tea room uses only two of these movements in its design. However, another screen system exists which makes use of all three movements in its design. This screen can be found at the Funairi room inside the Hiunkaku pavilion in Kyoto. The basic design of this screen is very similar to that of the 'Bosen' room, except the one used in the Funairi room is more mechanical, allowing for increased control of the environment. The 'Bosen' and Funairi rooms are both spaces meant for relaxation and for the enjoyment of nature. And so, for this reason they make use of highly adaptable screen systems to take advantage of changing environmental conditions. This is where we can find improvement for urban types of screens. By combining multiple movements in one screen system, it can start to improve its flexibility. Apart from this, the traditional design permits for all the panels to be removed if needed, giving the option to have a full view of the landscape. The final result would be a puzzle like screen system of movable panels with increased filtering capabilities in an ever-changing urban landscape.

\section{CONCLUSIONS}

In all aspects of Japanese traditional architecture, paper screens are incorporated as a way of increasing the adaptability of spaces. Whether in small or large rooms their applications play a significant part in enhancing the connection to one's surroundings by bringing focus to desired views while hiding others. Throughout the year they work to improve ventilation and illumination according to individual needs. Through the use of panels which can slide, swing, fold or be completely removed, 
as well as a combination of solid, opaque and transparent surfaces, the screen can transform itself to the needs of the moment. The characteristics of such a screen have also proven helpful in improving the perception of small spaces by redefining their boundaries through the imagination of every observer. The result is a space free of distractions with just enough information for each person to sit, relax and reimagine a room with limitless boundaries. Elements like the design of a railing imitating that of a boat, the treatment of interior paintings or the incorporation of the reflection of water ripples creates hints which have a big impact on the perception of space. By themselves, traditional screens have become effective tools in improving small spaces over the course of centuries, and thus making them a key element in contemporary Japanese design. In cities like Tokyo their use contributes to improving the quality of new constructions lacking outdoor environments. Urban spaces may be dark, confined, windy, and may consist of windows with no views or any number of other elements. For this reason a contemporary screen system needs to be able to react to each one of these by regulating the amount of views, light, ventilation and interaction with the environment. Traditional Japanese architecture has already shown us how screen systems work, and by creating a screen system which considers traditional Japanese principles, it can lead to a more adaptable system better suited for urban spaces. Overall, screen systems provide an opportunity to escape the hectic life of the city and at the same time create a space based on tranquility.

\section{REFERENCES}

[1] Kanji, N., Kobori Enshu: A Tea Master's Harmonic Brilliance, Kyoto Tsushinsha Press: Kyoto, pp. 54-65, 2009.

[2] Naoko, O. \& Mari, M., Discovering the Beauty of Traditional Kyoto. Casa Brutus, Takefumi Ishiwatari: Tokyo, pp. 66-67, 2007.

[3] Gisei, T., Kinzo, H., Invitation to Japanese Gardens, Mitsumura Suiko Shoin: Kyoto, pp. 60-63, 1960.

[4] Kanji, N., Personal communication, President of Nomura Landscape Laboratory, Nagoya Japan, 24 November 2009.

[5] John H. Martin, Phyllis G. Martin, Kyoto: A Cultural Guide, Tuttle Publishing, pp. 219-220, 2002.

[6] Tanizaki, J., In Praise of Shadows, Vintage Classics, p. 46, 1977.

[7] Beita, E., Ambigous Boundaries: A Japanese Way of Designing with Nature, Eco-Architecture 2010, Vol. 128, pp. 15-26, 2010. 